BRITO, M.L.A. et al. Operações e P\&D em uma associação de pequeno porte que atua com projetos. PUBVET, Londrina, V. 5, N. 40, Ed. 187, Art. 1259, 2011.

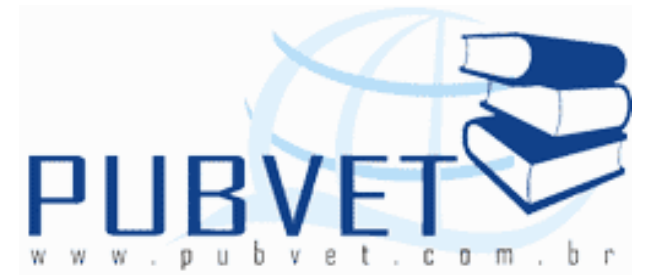

PUBVET, Publicações em Medicina Veterinária e Zootecnia.

\title{
Operações e P\&D em uma associação de pequeno porte que atua com projetos
}

\section{Max Leandro de Araújo Brito ${ }^{1}$, Tamara Patrícia Filgueira de Melo ${ }^{2}$, Sheila de Lima Cunha², Manoel Veras de Sousa Neto ${ }^{3}$}

\author{
${ }^{1}$ Docente do Depad-UFRN e mestrando em administração PPGA-UFRN. \\ ${ }^{2}$ Mestranda em administração PPGA-UFRN. \\ ${ }^{3}$ Docente do PPGA-UFRN.
}

\section{Resumo}

As funções organizacionais são indispensáveis para a manutenção das atividades de qualquer instituição, não importando o tamanho, muito menos tipos ou características. Duas importantes funções que se relacionam intimamente com o desenvolvimento dos produtos e serviços são a de operações, e a de pesquisa e desenvolvimento (P\&D). Levando em conta o contexto apresentado, a pesquisa objetiva caracterizar a execução das funções de operações, pesquisa e desenvolvimento em uma organização associativa de pequeno porte. A metodologia consiste na revisão da literatura que aborda as funções de operações, pesquisa e desenvolvimento, gerenciamento de projetos, terceiro setor e economia solidária, além de aplicação de um roteiro de entrevista semi-estruturado para a realização de uma entrevista em profundidade, tratando-se de uma pesquisa exploratória descritiva, tipo pesquisa diagnóstico, sendo predominantemente qualitativa. Dentre os 
BRITO, M.L.A. et al. Operações e P\&D em uma associação de pequeno porte que atua com projetos. PUBVET, Londrina, V. 5, N. 40, Ed. 187, Art. 1259, 2011.

resultados obtidos estão a percepção que a organização possui uma função de operações com dificuldades na movimentação fora da zona rural além de inexistência de utilização de computadores e Internet. Dessa forma a pesquisa aponta para dificuldade de movimentação de mercadoria por não se ter controle sobre os meios de transportes urbanos, e utilização de tecnologia antiga para o desenvolvimento de atividades. Uma das limitações para a realização da pesquisa é a dificuldade do encontro das atividades específicas de cada função organizacional devido ao tamanho reduzido da organização.

Palavras-chave: Produção; Tecnologia da Informação; Associativismo.

\title{
Operations and $R \&$ D in a association small that operates with projects
}

\begin{abstract}
Organizational functions are indispensable for the maintenance of activities ofany institution, regardless of size, much less type or characteristics. Two important functions that are closely related to the development of products and services are operating, and research and development ( $\&$ \&). Taking into account the context presented, the research aims to characterize the performance of the functions of operations, research and development in a small membership organization. The methodology is to review the literature that discusses the functions of operations, research and development, project management, third sector and social economy, and implementation of a roadmap for semi-structured to perform an in-depth interview, in the case is an exploratory research descriptive type diagnostic, predominantly qualitative. Among the results are the perception that the organization has an operations function with difficulties in moving out of rural areas in addition to lack of use of computers and the Internet. Thus, the research points to the difficulty of moving goods by not having control over the means of urban transport, and use old technology for the development of activities. One of the limitations of
\end{abstract}


BRITO, M.L.A. et al. Operações e P\&D em uma associação de pequeno porte que atua com projetos. PUBVET, Londrina, V. 5, N. 40, Ed. 187, Art. 1259, 2011.

the research is the difficulty of meeting the specific activities of each organizational function due to the small size of the organization.

Keywords: Production; Information Technology; Associations.

\section{INTRODUÇÃO}

Refletir sobre o desenvolvimento de uma organização leva a investigação sobre o andamento das funções de operações, além da verificação de como andam a pesquisa e desenvolvimento. Entender as tecnologias organizacionais e as aplicações das mesmas representa uma maneira confiável de observar se a organização está obtendo êxito na estruturação dos métodos utilizados para o desenvolvimento de suas atividades fins.

No caso de uma associação comunitária, pensar sobre a forma como são desempenhadas as atividades e o desenvolvimento de tecnologias (ou utilização das mesmas) na atualidade e futura pode revelar pontos fortes e fracos que tanto podem ser melhorados ou entendidos, aprimorando o desempenho da organização.

Raramente observa-se o funcionamento das operações em organizações associativas de pequeno porte. Embora nas últimas décadas, devido à diminuição do poder do Estado, essas organizações tenham surgido em maior quantidade, ainda não existe formalização, parametrização de atividades, o que muitas vezes dificulta, ou até mesmo impede contribuições e análises de quem tenta compreender a produção e logística nelas.

Da mesma forma ocorre com a pesquisa e desenvolvimento, pois mesmo que tenha havido repentinos avanços no registro de informações e principalmente na digitalização de conteúdo e pesquisas, ainda não é possível a disseminação dos conhecimentos informáticos de maneira uniforme para toda população. E levando em conta que a maior parte dos participantes de associações de pequeno porte no Rio Grande do Norte é formada por pessoas 
BRITO, M.L.A. et al. Operações e P\&D em uma associação de pequeno porte que atua com projetos. PUBVET, Londrina, V. 5, N. 40, Ed. 187, Art. 1259, 2011.

com renda baixa e de pouco nível instrucional, a utilização os recursos tecnológicos atuais fica reduzido.

Levando em conta o contexto apresentado acima surge o seguinte problema: como se dá o funcionamento das funções de operações, pesquisa e desenvolvimento em uma organização associativa de pequeno porte?

Parte-se da ideia de que o gerenciamento de projetos acontece dentro das funções organizacionais, visto que um dos focos da organização estudada é desenvolvimento e implantação de projetos. Salienta-se que pesquisa objetiva caracterizar a execução das funções de operações, pesquisa e desenvolvimento em uma organização associativa de pequeno porte.

O trabalho se estrutura com uma revisão inicial sobre terceiro setor, economia solidária, as funções de operações, pesquisa e desenvolvimento, e gerenciamento de projetos, seguida da metodologia, resultado e análises, e por fim as conclusões.

\section{TERCEIRO SETOR E ECONOMIA SOLIDÁRIA}

O governo compreende as organizações de serviço público, que administram o Estado e prestam serviços aos cidadãos, enquanto isso uma empresa é uma organização de negócios, que tem o objetivo de vender produtos e serviços e obter lucro, já o terceiro setor compreende as organizações de utilidade pública que têm origem na sociedade e não no governo (MAXIMIANO, 2008). Algumas organizações do terceiro setor não têm finalidade lucrativa, elas existem para provocar mudanças nos indivíduos e na sociedade (DRUCKER, 1997).

As organizações do terceiro setor tentam diminuir a destruição social ocasionada pelas demais. Para Lopes (2004) se existe uma contradição de fundo na própria necessidade de gerir uma política social associada a um modelo de desenvolvimento, é porque se constata que a intervenção políticoeconômica que o sustenta não é extensivamente dirigida a todos. Políticas sociais só existem em sociedades que reconhecem as desigualdades geradas 
BRITO, M.L.A. et al. Operações e P\&D em uma associação de pequeno porte que atua com projetos. PUBVET, Londrina, V. 5, N. 40, Ed. 187, Art. 1259, 2011.

pelo seu modelo de desenvolvimento e só são implantadas por governos comprometidos (ou pressionados pela população) com a diminuição ou com a superação dessas desigualdades.

De acordo com ele o Estado compõe, com a sociedade civil, a esfera pública. Diminuir a presença do Estado é diminuir seu peso na definição das necessidades sociais. Embora essa estratégia dê a impressão de maior autonomia da sociedade civil na determinação de suas necessidades sociais, o que ocorre efetivamente é que o Estado busca estabelecer sua função regulamentadora, o exercício de administrar e dirigir, mas se exime progressivamente da provisão social.

O autor destaca que é necessária a promoção de um modelo de organização de segmentos participativos da sociedade que implique em uma nova configuração das políticas sociais, capaz de produzir estratégias amplas de enfrentamento da exclusão social, de forma a inscrever os interesses das maiorias nos processos de decisão política.

Pois no movimento contemporâneo de ampliação da esfera pública, proliferam presenças diversificadas de agentes políticos, culturais, econômicos e sociais, com ações ou discursos nem sempre convergentes na criação de modelos dinâmicos de organização. Dessa forma, o estabelecimento da interlocução pública nem sempre se direciona para possibilidades de deliberação em conjunto das questões que dizem respeito a um destino coletivo.

Para melhorar a vida de pessoas que se interessam por uma produção humanizada, voltada para divisão igualitária dos frutos do trabalho honesto desenvolveu-se dentro do terceiro setor a economia solidária que de acordo com Coutinho et. al. (2005) vem se estruturando hoje através de associações e cooperativas.

As associações são quaisquer grupos sociais unidos em torno de uma finalidade específica e com estatuto orientado pelo Código Civil Brasileiro de 2002. No Brasil, o associativismo ainda está em processo de constituição como movimento social forte e articulado. 
BRITO, M.L.A. et al. Operações e P\&D em uma associação de pequeno porte que atua com projetos. PUBVET, Londrina, V. 5, N. 40, Ed. 187, Art. 1259, 2011.

\section{OPERAÇÕES}

Com a função de operações a fabricação do produto/serviço torna-se possível. Apesar de atualmente ser clara a distinção entre logística e produção, essas duas palavras trabalham unidas quando trata-se das operações de uma organização.

Para Maximiano (2008) o objetivo básico da função produção é transformar insumos para fornecer o produto ou serviço da organização aos clientes usuários ou público-alvo, tendo dessa forma, foco na utilização dos inputs para gerar outputs.

A função de produção se preocupa em transformar insumos em produtos úteis, acrescentando, valor a determinada entidade. Sendo, portanto uma atividade básica de praticamente todas as organizações (MEREDITH; SHAFER, 2002).

O setor de produção é fundamental também para as atividades pessoais e profissionais das pessoas, independente dos cargos que ocupam, visto que as pessoas também devem operar de forma produtiva, acrescentando valor aos insumos e produzindo produtos de qualidade (MEREDITH; SHAFER, 2002).

$\mathrm{Na}$ gestão dos fluxos entre a produção e o marketing se encontra a logística, de acordo com Dornier et. al. (2000). Segundo estes autores, a abordagem da estrutura organizacional orientada funcionalmente separa as atividades de uma empresa em um número limitado de divisões organizacionais. O processo logístico, nesse contexto, atravessa todas as áreas funcionais, criando assim importantes interfaces.

É necessária inovação para que a logística aconteça de forma adequada dentro de uma organização (KOBAYASHI, 2000). O processo relativo ao fluxo dos materiais estende-se do abastecimento até o cliente final, dessa forma, para inovar o fluxo dos materiais são necessárias atividades que vão além das funções estreitamente interessadas, sendo necessários sistemas informativos para auxiliar no processo. 
BRITO, M.L.A. et al. Operações e P\&D em uma associação de pequeno porte que atua com projetos. PUBVET, Londrina, V. 5, N. 40, Ed. 187, Art. 1259, 2011.

A inovação da logística para obter a satisfação dos clientes está na inovação dos processos. Procurar transformar as organizações mediante a transformação da oferta aos clientes implica no esforço para inovar na logística.

Cristopher (2007) enxerga a logística como um processo de gerenciamento estratégico da compra, do transporte e da armazenagem de matérias-primas, partes e produtos acabados (além dos fluxos de informação relacionados) por parte da organização e de seus canais de marketing, de tal modo que a lucratividade atual e futura sejam maximizadas mediante a entrega de encomendas com o menor custo associado. Esse conceito é parecido com o defendido por Pozo (2002), que informa que a abordagem logística tem como função estudar a maneira como a administração pode otimizar os recursos de suprimento, estoques e distribuição dos produtos e serviços com que a organização se apresenta ao mercado por meio de planejamento, organização e controle efetivo de suas atividades correlatas, flexibilizando os fluxos dos produtos oferecidos.

Vale salientar que, apesar da abrangência da logística, ela é diferente da gestão da cadeia de suprimentos. A gestão de cadeias de suprimentos (cadeia de valor ou demanda) compreende empresas que colaboram para alavancar posicionamento estratégico para melhorar a eficiência das operações (BOWERSOX; CLOSS; COOPER, 2006). Já a logística é um subconjunto e ocorre dentro da estrutura mais abrangente de uma cadeia de suprimentos, sendo um processo que gera valor a partir da configuração do tempo e do posicionamento do inventário; e a combinação da gestão de pedidos de uma empresa, do inventário, do transporte, do armazenamento, do manuseio e embalagem de materiais, enquanto procedimentos integrados em uma rede de instalações.

Portanto, no desenvolvimento das operações de uma organização devese estar atento para a produção enquanto transformadora de recurso e para a logística no momento que se faz necessária enquanto interface entre as 
BRITO, M.L.A. et al. Operações e P\&D em uma associação de pequeno porte que atua com projetos. PUBVET, Londrina, V. 5, N. 40, Ed. 187, Art. 1259, 2011.

diversas funções da organização, principalmente a de marketing e a de produção.

\section{PESQUISA E DESENVOLVIMENTO}

Para a organização se desenvolver dentro do mundo competitivo onde está inserida é fundamental a existência de constantes inovações, mudanças e adaptações. No acompanhamento de novos paradigmas existe a função de pesquisa e desenvolvimento, representada muitas vezes pela utilização e tratamento da tecnologia da informação.

De acordo com Maximiano (2008) o objetivo básico de pesquisa e desenvolvimento é transformar as informações de marketing, as ideias originais e os avanços da ciência em produtos e serviços, estando dessa forma associada à inovação ou à ideia de agregar valor ao produto e serviço a partir da informação.

Pode-se afirmar que as organizações usam as informações como um recurso, como um ativo ou como um produto (GORDON; GORDON, 2006). Quanto à informação como recurso, têm-se o dinheiro, pessoas, matériasprimas, equipamentos ou tempo, onde a informação pode servir com um insumo na produção de bens e serviços. Quanto à informação como um ativo têm-se a propriedade de uma pessoa ou de uma organização que contribui para os resultados de uma instituição, os gestores podem visualizar a informação como um investimento que eles podem usar estrategicamente para dar à sua organização uma vantagem sobre seus competidores.

Quanto à informação como produto, as organizações também podem vender informações, o resultado de seu processo produtivo, como um produto ou serviço, ou como componente embutido em um produto, visto que na economia orientada para serviços, um número crescente de empresas encara a informação desta forma.

Barrene Chea (2001) destaca que as instituições precisam de recursos para comunicar, localizar e explorar informações, assegurar condições 
BRITO, M.L.A. et al. Operações e P\&D em uma associação de pequeno porte que atua com projetos. PUBVET, Londrina, V. 5, N. 40, Ed. 187, Art. 1259, 2011.

comerciais favoráveis, fazer pedidos eficientemente e solicitar rápida assistência de seus fornecedores. Nos relacionamentos externos as organizações podem usar a Internet para disseminar informações a consumidores e a outras instituições, solicitar e obter feedback quanto a seus produtos e serviços e interagir com seus parceiros de negócios. Evidentemente também podem usar a Internet para representá-las diretamente perante os clientes e realizar transações comerciais sem a presença de intermediários.

No tratamento da informação está a administração de TI, que é composta por um conjunto de regras que devem ser seguidas por quem quiser se dar bem gerenciando uma área de informática e o relacionamento com seus usuários (CRUZ, 1998). A tecnologia de informação é todo e qualquer dispositivo que tenha a capacidade de tratar dados e/ou informações, tanto de forma sistêmica como esporádica, quer esteja aplicada no produto, quer esteja aplicada no processo.

Conclui-se que para o desenvolvimento da pesquisa e desenvolvimento torna-se indispensável a utilização e tratamento da informação, que pode ser tanto vista como recurso, ativo ou produto dentro do contexto organizacional.

\section{GERENCIAMENTO DE PROJETOS}

A competição global, o enxugamento das empresas e dos mercados emergentes, dentre outro motivos, fizeram do gerenciamento de projetos uma importante vantagem competitiva na maioria das organizações (LARSON; DREXLER JR, 2010).

Nesse novo ambiente organizacional o uso de recursos tecnológicos como computador, celulares, tonou-se rotineiro, e a aprendizagem através de meios virtuais apareceu como uma ferramenta cada vez mais comum no sistema de ensino (ORLY, 2007).

Na economia internacional é notável o contínuo aumento da participação da atividade do gerenciamento de projetos na economia global (YATIM; BREDILLET; RUIZ, 2009). 
BRITO, M.L.A. et al. Operações e P\&D em uma associação de pequeno porte que atua com projetos. PUBVET, Londrina, V. 5, N. 40, Ed. 187, Art. 1259, 2011.

Esse gerenciamento pode ser entendido como a aplicação de modernas técnicas de gestão e sistemas para a execução de um projeto do início ao fim para atingir determinados objetivos de escopo, qualidade, tempo e custo (LARSON; DREXLER JR, 2010). Ele tem sido espalhado por todo o mundo e abrangendo uma grande variedade de países com diferentes especificidades sociais, econômicas e culturais.

\section{METODOLOGIA}

O presente trabalho se propõe a caracterizar a execução das funções de operações, pesquisa e desenvolvimento em uma organização associativa de pequeno porte. Portanto trata-se de uma pesquisa teórica, exploratória (ROESCH, 2005), descritiva, tipo pesquisa-diagnóstico.

A população interna desta pesquisa compreende todos os participantes de uma associação comunitária situada na cidade de Acari, estado do Rio Grande do Norte, em um total de trinta e duas pessoas. Por se tratar de uma pesquisa predominantemente qualitativa e pelo fato do presidente da associação ter o conhecimento requerido para o desenvolvimento e aprofundamento da pesquisa, optou-se por conveniência em escolhê-lo para responder a entrevista.

Os dados primários foram obtidos pelo próprio pesquisador através da entrevista. Já os secundários foram adquiridos através de informações de atas e relatórios da instituição.

Optou-se pela aplicação de um roteiro de entrevista semiestruturado para a realização de uma entrevista em profundidade. Nesse roteiro constam 4 tópicos sobre o funcionamento das funções de operações, pesquisa e desenvolvimento, e dois sobre aspectos críticos e de sucesso da organização.

Foram realizadas análises qualitativas através da análise do discurso (BARDIN, 2002), sem a presença de softwares específicos. 
BRITO, M.L.A. et al. Operações e P\&D em uma associação de pequeno porte que atua com projetos. PUBVET, Londrina, V. 5, N. 40, Ed. 187, Art. 1259, 2011.

\section{RESULTADOS E ANÁLISES}

A Entre Vales é uma organização com menos de dez anos de existência, que concentra suas atividades na zona rural. Seus trinta e dois participantes são voluntários que se reúnem mensalmente para deliberar sobre assuntos pertinentes para a associação. Essa organização está voltada para a minimização dos impactos da seca nas atividades agropecuárias e fortalecimento da união dos associados em torno de idéias e valores comuns. Os principais serviços desenvolvidos e prestados pela associação são desenvolvimento de projetos, reuniões, e implantação de projetos.

Mesmo sem possuir declarações de visão, missão e valores, possui uma divisão de atividades sistêmica, apropriada para a estrutura das organizações sociais. A presidência, através do desenvolvimento das reuniões e comando das ações de melhorias definidas nelas, se conecta com a secretaria, que se responsabiliza por toda a burocratização, registro e armazenamento das informações da associação. Por sua vez, a secretaria se interliga com a tesouraria, que cuidará de distribuir, adquirir e armazenar recursos a partir das informações definidas e registradas durante as reuniões. O conselho fiscal, por promover a verificação das destinações dos recursos da associação, está ligado à tesouraria. Esse conselho fiscal presta contas aos associados, que definem a permanência da presidência. Todos os associados possuem o mesmo peso de voto e têm liberdade para opinar a qualquer momento.

De acordo com a pesquisa vê-se "a Entre Vales como uma organização pequena porque o funcionamento dela é ocasional, e quando acontecem as reuniões é que ela realmente se movimenta".

Esse modo tranquilo de movimentar a associação pode ser fruto da não obrigatoriedade de produção no voluntariado, mas desenvolvimento de atividades a partir da espontaneidade, como fala a literatura, um compromisso individual com os objetivos e atividades necessárias para o desenvolvimento da instituição. 
BRITO, M.L.A. et al. Operações e P\&D em uma associação de pequeno porte que atua com projetos. PUBVET, Londrina, V. 5, N. 40, Ed. 187, Art. 1259, 2011.

Vê-se que existe um entendimento de possíveis motivos para a inibição do desenvolvimento da associação e da transformação em cooperativa, dentre os quais o funcionamento de forma não contínua no que tange a presença física diária, e o desenvolvimento de atividades estreitamente relacionado às reuniões, dificultando talvez a construção de trabalhos em períodos entre as reuniões. Vê-se que o estilo de administração é participativo devido a grande valorização das reuniões e consequentemente das ideias geradas nas mesmas. Percebe-se que a organização tem uma estrutura integrada, que talvez seja fruto do tamanho reduzido, ainda possuindo filosofias estruturais muito parecidas com as ideias do idealizador, o que leva a crer que ou ela não se desenvolveu o suficiente para tomar outros rumos ou as percepções impostas por esse idealizador ainda prevaleçam e sejam respeitadas por se tratar de uma pessoa empenhada na manutenção da instituição.

Nota-se que a organização possui foco na eficácia. Embora as reuniões ocorram esporadicamente, a presença de resultados garante a continuidade do desenvolvimento da organização. Assim, aproveita-se o contexto do trabalho voluntário para coordenar as ações associativas de forma menos cansativa e/ou rotineira, agradando tanto fins organizacionais (com a presença do desenvolvimento de atividades por resultados) quanto o fator humano (que por ser uma atividade sem alto retorno financeiro é mais interessante que aconteça entre outras atividades que trazem renda maior, ao invés de acontecer em substituição delas).

Nesse ambiente de flexibilidade de execução de atividades existe o incentivo à inovação e à mudança. Talvez pelo caráter de certa forma descompromissado dos associados, visto que se preocupam mais com a organização apenas nos períodos de realização das reuniões, as inovações e mudanças não sejam implantadas com efetividade pela associação. Embora o processo criativo dos associados seja motivado e haja a possibilidade de idéias inovadoras serem utilizadas de forma rápida, antes da maturação essas ideias são substituídas por outras que possivelmente alcançarão maior sucesso. A 
BRITO, M.L.A. et al. Operações e P\&D em uma associação de pequeno porte que atua com projetos. PUBVET, Londrina, V. 5, N. 40, Ed. 187, Art. 1259, 2011.

troca de informação e as reflexões também favorecem a alteração constante de pensamentos e métodos de execução de atividades associativas.

Analisando a organização quanto à sustentação do desenvolvimento no futuro, entende-se que se ela continuar com os principais serviços oferecidos atualmente pode-se utilizar desse método de reuniões periódicas para o desenvolvimento de suas atividades finais. Mas levando-se em conta que os projetos focados na atualidade estão voltados para aquisição de recursos a fundo perdido, a auto sustentação pode depender de outras ações desenvolvidas pelo conjunto dos associados como a agropecuária, a fruticultura.

Nota-se que no desenvolvimento das operações de uma organização são necessários tanto cuidados com a produção quanto com a logística do produto e/ou serviço. De acordo com a entrevista "o acesso às reuniões é livre, todos os interessados podem participar das reuniões. As pessoas chegam à reunião com a ajuda de moto, cavalo". Quanto ao "transporte dos produtos dos associados para a comercialização na cidade", "(..) se dá principalmente através do caminhão que recolhe o leite nos sítios e revende para uma cooperativa em uma cidade vizinha", "(...) ou através da caminhoneta que transporta estudantes para o estudo na zona urbana de Acari". Também é destacado que os principais serviços desenvolvidos e prestados pela associação são desenvolvimento de projetos, reuniões, e implantação de projetos.

Fica notório que, conforme exposto na literatura, a função produção da associação transforma insumos, como idéias, para fornecer serviços aos clientes usuários, como desenvolvimento de projetos, tendo dessa forma um foco na utilização dos inputs para gerar outputs. A logística, conforme bibliografia consultada, tanto da associação quanto dos associados está na gestão dos fluxos entre a produção e o marketing - embora que esse marketing seja quase que exclusivamente a venda ou oferecimento dos produtos e serviços.

Percebe-se a utilização de recursos característicos do campo como meio de transporte, no caso o animal. Talvez esse fator interfira no tempo para se 
BRITO, M.L.A. et al. Operações e P\&D em uma associação de pequeno porte que atua com projetos. PUBVET, Londrina, V. 5, N. 40, Ed. 187, Art. 1259, 2011.

chegar ao local das reuniões, embora que, devido à rusticidade, pode-se chegar a locais de difícil penetração. Esse apego ao modo de transporte mais rural pode interferir na dependência que se tem do transporte oferecido pela zona urbana. Embora os associados utilizem um meio de transporte (do qual possuem domínio físico) tipicamente rural para participarem das reuniões da associação, quando comercializam produtos ou buscam informações sobre projetos na zona urbana da cidade são obrigados, em grande parte, a dependerem de meios dos quais não possuem controle de tempo, movimento, itinerário.

Destaca-se que o desenvolvimento dos serviços da associação se dá através das reuniões, que necessitam da presença dos associados. Dentro da reunião são apontadas diversas ideias que representam diferentes visões das realidades produtivas e/ou financeiras de cada associado. Com a união das diversas ideias a presidência mantém, juntamente com os registros da secretaria, o foco da reunião, tentando unir ideias similares para a formação de conhecimento e propostas que gerem possibilidades de projetos, ou outro serviço que seja viável cumprir.

Para que os associados cheguem ao recinto de troca de ideias é fundamental o domínio sobre meios de transportes visto que as dimensões dos sítios formadores da associação são grandes. Mas é fundamental também o domínio sobre transportes para escoar a produção dos associados. Talvez a utilização de conduções próprias de médio e grande porte (carros e caminhonetas) não seja adequada à realidade financeira dos associados. Mas o aumento das opções de transportes é fundamental, visto que trata-se de um investimento para aquisição de divisas futuramente. Talvez a multiplicação de transportes de pequeno porte, como motos, seja uma solução temporária para a comodidade de locomoção entre campo e cidade.

Acredita-se que ainda não seja o momento da associação possuir uma condução própria. Para se ter um transporte comum a todos seria interessante produzir suficientemente para manter um grau de utilização alto desse veículo, 
BRITO, M.L.A. et al. Operações e P\&D em uma associação de pequeno porte que atua com projetos. PUBVET, Londrina, V. 5, N. 40, Ed. 187, Art. 1259, 2011.

visto que o investimento em um transporte caro que ficará a maior parte do tempo parado pode resultar em prejuízo ou falta de retorno.

Pode-se destacar como reflexo das falhas logísticas na comunicação entre a zona rural e urbana a não comercialização de produtos perecíveis em todas as horas do dia. A venda de produtos como leite e hortaliças está associada à frequência dos transportes movimentados por terceiros, o que exige adequação de horários. Dessa forma, os produtores associados não têm liberdade de escolher as horas que querem trabalhar em determinadas tarefas, pois têm que acompanhar prazos exigidos ou cumpridos por outros.

Portanto, a utilização de meios de transportes característicos do campo pode ajudar na movimentação dentro do meio rural, visto que embora se perda tempo, pode-se adentrar em regiões mais inóspitas. Já quando se tem a necessidade de comercialização e aquisição de informações sobre projetos na zona urbana, as dificuldades aumentam. Para os que possuem moto o trânsito fica mais fácil, mesmo sabendo-se que não é um meio de transporte a ser utilizado para grandes cargas.

A pesquisa e desenvolvimento se associa muito fortemente à Tecnologia da Informação, à inovação e a diversos tipos de tecnologias dentro da associação. Os dados coletados informam que "dentre as tecnologias utilizadas pela associação e seus membros pode-se citar a bomba elétrica do poço que abastece os três vales, e os livros de registros utilizados para confecção das atas".

Percebe-se que na associação, conforme dita a literatura, a pesquisa e desenvolvimento transforma os avanços da ciência em produtos e serviços, estando dessa forma associados à idéia de agregar valor ao produto e serviço a partir da informação - apesar do tratamento da informação ainda ser rústico.

Nota-se que a tecnologia apresentada pela associação, apesar de representar um avanço dos métodos tradicionais ainda utilizados (como catavento e memória humana) atinge os efeitos para os quais se destina (bombeamento rápido de água e registro de informação), apesar de não ser compatível com o que já é requerido na zona urbana (textos digitalizados, 
BRITO, M.L.A. et al. Operações e P\&D em uma associação de pequeno porte que atua com projetos. PUBVET, Londrina, V. 5, N. 40, Ed. 187, Art. 1259, 2011.

água tratada). Existe e intenção de aperfeiçoamento, apesar de se consegui-lo de forma satisfatória para a realidade vivenciada, não exatamente por completo se analisarmos as exigências da modernidade.

É perceptível que a utilização de tecnologias de registro de informação, mesmo que relativamente atrasadas, são de grande ajuda para a elaboração de projetos. Através dos registros efetuados pela secretaria é que pode-se aglomerar as ideias das reuniões ou pensamentos anteriores. Com esses registros tem-se a possibilidade de se rever caminhos para construção e desenvolvimento dos projetos, visto que funcionam como um banco de dados de idéias que podem ser utilizadas a partir da leitura.

Dessa forma, a informação dentro da associação pode ser vista como um recurso pois, de acordo com a literatura, pode servir como um insumo na produção de serviços, no caso ajuda no direcionamento de idéias para elaboração de projetos.

Conforme informado pela bibliografia, a Internet é um fator impulsionador da Tecnologia da Informação sendo indispensável para a disseminação de ideias e desenvolvimento de comunicações. Mas na associação a Internet é pouco utilizada, visto que não se possui computador e muitos associados não acessam ou nunca acessaram a Internet. A utilização da Internet pode ser uma alternativa para o desenvolvimento de novas ideias e projetos, vista a vastidão de conhecimento que se pode adquirir a partir dela. Mesmo que não se tenha computador com acesso à Internet na associação, pode-se utilizar os serviços de locais de acesso à Internet para atualização e aquisição de conhecimento. Vê-se que a associação ainda não possui condições financeiras para a compra e manutenção de computador com acesso à Internet.

Percebe-se que os associados fecham os olhos para a inclusão digital pelo fato dela não ser tão próxima dos mesmos. Na zona rural a tecnologia utilizada para se produzir na agropecuária e outras atividades não é tão avançada tecnologicamente o que não exige uma adequação constante às novas tecnologias, dentre as quais a informática. 
BRITO, M.L.A. et al. Operações e P\&D em uma associação de pequeno porte que atua com projetos. PUBVET, Londrina, V. 5, N. 40, Ed. 187, Art. 1259, 2011.

Vive-se ainda uma aproximação maior a mídias como televisão ou rádio, o que já é um avanço, levando-se em conta que até pouco tempo atrás não se tinha energia elétrica em alguns sítios formadores da associação.

Nota-se que a aceitação das informações trazidas pela televisão e pelo rádio se dá de maneira quase que instantânea. Confia-se muito nas idéias de locutores e de programas de TV. Dessas mídias são absorvidas informações como preços de produtos, notícias policiais, tendências da moda.

Se de um lado o preço compensa a utilização e eficiência dos recursos atualmente utilizados, por outro tem-se que perceber as exigências impostas pelo desenvolvimento tecnológico e de tratamento das informações, que embora sejam muitas vezes passageiros, exigem atualizações.

\section{CONCLUSÃO}

Por fim, a pesquisa sobre o funcionamento das funções de operações, pesquisa e desenvolvimento da organização associativa de pequeno porte aponta para dificuldade de movimentação de mercadoria por não se ter controle sobre os meios de transportes urbanos, e utilização de tecnologia antiga para o desenvolvimento de atividades.

Dentre as limitações encontradas para a realização da pesquisa está a dificuldade no encontro das atividades específicas de cada função organizacional devido ao tamanho reduzido da organização.

Para novas abordagens sobre o tema, sugere-se que se valorize o mapeamento de aspectos pessoais dos participantes da organização, através de uma visão antropológica da concepção deles sobre o funcionamento de cada função organizacional estudada na pesquisa, não obrigatoriamente para traçar a situação da instituição, mas para entender a percepção deles sobre a situação na qual ela se encontra. 


\section{REFERÊNCIAS}

BARDIN, L. Análise de conteúdo. Lisboa: Edições 70, 2002.

BERRENE CHEA, M. J. E. Business ou fora do negócio. São Paulo: Makron, 2001. BOWERSOX, D. J.; CLOSS, D. J.; COOPER, M. B. Gestão logística de cadeias de suprimentos. Porto Alegre: Brookman, 2006.

COUTINHO, M. C. et. al. Novos caminhos, cooperação e solidariedade: a psicologia em empreendimentos solidários. Psicologia \& Sociedade, Porto Alegre, v. 17, n.1, p. 7- 13, jan./abr. 2005. Quadrimestral.

CRISTOPHER, M. Logística e gerenciamento da cadeia de suprimentos: criando redes que agregam valor. 2.ed. São Paulo: Thomson Learning, 2007.

CRUZ, T. Sistemas de informações gerenciais: tecnologia da informação e a empresa do século XXI. São Paulo: Atlas, 1998.

DORNIER, P. et al. Logística e operações globais. São Paulo: Atlas, 2000.

DRUCKER, P. F. Administração em organizações em fins lucrativos: princípios e práticas. 4. ed. São Paulo: Pioneira, 1997.

GORGON, S. R.; GORDON, J. R. Sistemas de informação: uma abordagem gerencial. Rio de Janeiro: LTC, 2006.

KOBAYASHI, S. Renovação da logística: como definir estratégias de distribuição física global. São Paulo: Atlas, 2000.

LARSON, E.; DREXLER JR, J.A. Project management in real time: a service-learning project. Journal of Management Education, v. 34, n. 4, p. 551-573, ago. 2010.

LOPES, J. R. Terceiro setor: a organização das políticas sociais e a nova esfera pública. São Paulo em Perspectiva, São Paulo, v.18, n.3, p. 57-66, jul./set. 2004. Trimestral.

MAXIMIANO, A. C. A. Introdução à administração. 7. ed. São Paulo: Atlas, 2008.

MEREDITH, J. R.; SHAFER, S. M. Administração da produção para MBA's. Porto Alegre: Bookman, 2002.

ORLY, M. Multicultural e-learning project and comparison of teachers', student teachers' and pupils' perceptions about e-learning. Multicultural Education \&Technology Journal, v. 1, n. 3, p. 178-191, 2007.

POZO, H. Administração de recursos materiais e patrimoniais: uma abordagem logística. 2.ed. São Paulo: Atlas, 2002.

ROESCH, S. M. A. Projeto de estágio e de pesquisa em administração: guia para estágios, trabalhos de conclusão, dissertações e estudos de caso. 3.ed. São Paulo: Atlas, 2005.

YATIM, F.; BREDILLET, C. N.; RUIZ, P. Investigating the deployment of project management: a new perspective based on the concept of certification. International Journal of Managing Projects in Business, v. 2, n. 3, p. 445-454, 2009. 